\title{
Human Growth Hormone: Ethical and Economic Considerations of Use and Misuse
}

Martin M. Zdanowicz

\section{OBJECTIVE:}

To discuss the evolution of human growth hormone as an important therapeutic agent, highlighting its potential for misuse and abuse and including a discussion of economic and ethical considerations facing health care providers in using human growth hormone as a therapeutic agent.

\section{DATA SOURCES:}

Scientific, clinical, and pharmacy literature.

\section{STUDY SELECTION:}

Not applicable.

\section{DATA EXTRACTION:}

Not applicable.

\section{DATA SYNTHESIS:}

This article chronicles the progression of

\begin{abstract}
human growth hormone as a therapeutic drug from its beginning in the 1950 s through its current recombinant human form. Current clinically accepted indications for this drug are discussed, along with several recently investigated uses that have stirred controversy among physicians, insurance companies, and managed care organizations from both economic and ethical standpoints.
\end{abstract}

\section{CONCLUSION:}

While recombinant human growth hormone is a valuable drug in a number of clinical conditions such as growth failure Turner's syndrome, and renal failure, its use in other conditions such as short stature remains controversial and is a subject of debate between physicians and

\begin{abstract}
health care organizations that must carefully weigh the great expense of growth hormone therapy against the uncertain benefits and potential for serious side effects in these conditions. In addition, widespread black market availability of human growth hormone has contributed to the abuse of this agent as a youthpreserving and strength-enhancing product while clouding its potential future usefulness in a number of human wasting conditions associated with surgery, trauma, burns, AIDS, and osteoporosis.
\end{abstract}

\section{KEY WORDS:}

Human growth hormone, Uses, Abuse, Economics, Ethics.

J Managed Care Pharm 1997; 3:448-52.
Recombinant bioengineering technology has made pure, safe human Growth Hormone (hGH) available to physicians for nearly a decade. In that time, recombinant $\mathrm{hGH}$ has proven to be a valuable therapeutic agent in the treatment of growth deficiency resulting from a number of disorders. When used properly, hGH yields excellent results with very minimal side effects. The wider availability of human Growth Hormone as a result of recombinant biotechnology has allowed scientists to explore other potential uses for this hormone, including its role in the aging process and the possibility that it actually may alter the way in which we age. ${ }^{1}$ Other potential applications of hGH currently being investigated include its use in osteoporosis and wasting of body tissues, which occurs with prolonged illness or following trauma or burns. ${ }^{2}$ At the same time, wider availability of hGH has meant a greater potential for its abuse by those exploiting the hormone as a 'fountain of youth' or for its possible body-building effects. ${ }^{3}$ However, the attention focused on the limited abuse of hGH should not overshadow its current or future value as an important therapeutic agent.

\section{HUMAN GROWTH HORMONE AND GROWTH DISORDERS}

Growth hormone is one of the main components involved in stimulating growth during childhood and adolescence. Released from the pituitary gland as we sleep, growth hormone acts as a powerful growth-promoting agent. The greatest amount of growth hormone release occurs during adolescence, which is the time when the human body grows most rapidly. Growth hormone has a

MARTIN M. ZDANOWICZ, Ph.D., Assistant Professor of Pharmacology, Department of Pharmaceutical Sciences, Massachusetts College of Pharmacy and Allied Health Sciences, Boston.

AUTHOR CORRESPONDENCE: Martin M. Zdanowicz, Ph.D., Department of Pharmaceutical Sciences, Massachusetts College of Pharmacy and Allied Health Sciences, 179 Longwood Avenue, Boston, MA 02115 
stimulatory effect on many cells and tissues of the body, but it particularly is active in increasing the length of long bone as well as increasing the thickness of many soft tissues such as skin. ${ }^{4}$ Abnormal growth hormone production can dramatically alter the way a person grows. Over-production of growth hormone during childhood and adolescence can lead to excessive growth of long bones resulting in a person who literally is a giant. If the over-production of growth hormone continues unchecked past the time when long bones fuse at adolescence, a condition called acromegaly results. In acromegaly, the fused bones continue to grow in thickness, with resulting deformation of the limbs, face, and extremities. On the other hand, underproduction or deficiency of growth hormone during a person's growing years can result in slow growth, belownormal height, and, in the extreme, dwarfism.

The possibility of using exogenous sources of growth hormone to treat children who do not produce enough of their own first was explored in the 1950s when growth hormone extracted from human cadaver pituitary glands was successfully used to treat children with growth hormone deficiency. However, the difficulty and expense involved in obtaining human growth hormone meant that only children with marked deficiency of growth hormone could receive growth hormone therapy. In addition, one unfortunate outcome of early growth hormone therapy involved a small number of patients receiving cadaveric hGH who later developed a disorder called Creutzfeldt-Jacob syndrome. These patients suffered a progressive destruction of their nervous tissue by a virus that contaminated the growth hormone preparation., 5.6

In the 1980s recombinant DNA technology enabled scientists to take the genes for hormones such as growth hormone or insulin and insert them into harmless $E$. coli bacteria. These bacteria then acted as miniature factories that produced large quantities of pure hormone. As a result of this biotechnology', we now have the ability to produce a virtually unlimited supply of pure and safe human hormones that can be used to treat disease. This increased availability of safe hGH means that its therapeutic uses can be expanded to include a number of other disorders that affect growth in children such as Turner's syndrome (a chromosomal defect), growth hormone deficiency, and kidney failure. ${ }^{7.8}$ A number of scientific and clinical studies have led to a general consensus among physicians that growth hormone treatment is both beneficial and safe to use in these growth disorders. $5.78,13$

In children with Turner's syndrome, studies from Sweden, Europe, and the U.S. have reported marked stimulation of growth velocity in these patients when treated with growth hormone..$^{7.813}$ In growth hormone-deficient children, growth hormone therapy results in marked stimulation of growth velocity (from approximately $4 \mathrm{~cm} /$ year to $10 \mathrm{~cm} /$ year) and, more important, significant increases in final adult height when compared to the predicted height without growth hormone or to the height of untreated patients. ${ }^{7}$ The increased availability of growth hormone also has meant the expansion of growth hormone therapy to include cases, such as familial and idiopathic short stature, where its use remains controversial. ${ }^{9}$ While two key Swedish and Dutch studies of growth hormone therapy in children with short stature reported significant increases in growth velocity during the first year of treatment, many patients required higher doses of growth hormone to maintain these growth velocities in subsequent years. ${ }^{10,11}$ Despite the increased growth velocity reported in these studies, the improvements seen in final predicted adult heights were only minimal. The mulitcenter Genentech Collaborative Study carried out in the U.S. likewise reported significant increases in growth velocity of children with short stature; however, this study did show significant improvements in the final height of these patients. ${ }^{12}$

Regardless of the clinical effects, whether it is ethical or appropriate to prescribe growth hormone for. children who are short but have no abnormality of growth hormone production remains uncertain. If both of the child's parents are shorter than average and there is a family history of below-average height, is the physician justified in giving the child growth hormone therapy so that he or she can achieve a 'normal' height? To address these concerns, a group of pediatric endocrinologists from the Minneapolis-St. Paul area developed consensus guidelines for the diagnosis, monitoring, and care of children with short stature. The purpose of their guidelines was twofold: (1) to help primary care physicians clarify their role in the diagnosis and monitoring of children with short stature; and (2) to provide health maintenance organizations and insurance companies with a standard for the care of children with short stature and the use of growth hormone therapy. ${ }^{13}$

Several factors must be considered concerning the use of hGH therapy in children who may be of short stature. First are the social and psychological factors. Society places a premium on height. From earliest childhood, Americans are reminded constantly that the attainment of height is a desirable goal. The importance placed on height may have longterm social and emotional implications for shorter individuals. Children of short stature may suffer undue stress from peers or parents because of their height. ${ }^{10,11}$ In later life, there is evidence to suggest that people of short stature actually may be discriminated against in the job market. Studies also have reported that people of short stature may be earning less money in their profession than taller colleagues with similar qualifications and experience. And researchers have reported that people of short stature generally are less happy with their bodies than people of average or above-average height and may believe themselves to be less attractive to the opposite sex because of their height. ${ }^{9,14,15}$

A second factor to consider is the cost of prolonged growth hormone therapy, which can range from $\$ 13,000$ to $\$ 30,000$ per year. The cost of this therapy and the decision about when to use it is a matter of both debate and concern for physicians, insurance companies, managed care organizations, and pharmacy benefit management companies. 
A third factor is the question of whether or not long-term growth hormone therapy really works for shorter-statured individuals. Although there is considerable evidence supporting the short-term benefits of growth hormone in stimulating growth, it may be years until sufficient data is collected to prove that this therapy leads to an actual increase in the final height of children with short stature, which of course is the ultimate goal. Last, and perhaps most important, is the need to consider the possibility of side effects from growth hormone treatment. In controlled human studies where growth . hormone was used to replace or supplement hormone that was missing from the body, the occurrence of side effects was low. ${ }^{1,16,17}$ However, among the side effects reported was an increase in blood sugar, salt and water retention, carpal tunnel syndrome, and development of antibodies to growth hormone. ${ }^{1,7,8,16,17,18}$ A more serious cause for concern was raised in several clinical studies in which growth hormone therapy was associated with an increased occurrence of leukemia and tumors in patients receiving the hormone. ${ }^{19,20}$ However, the findings of these studies remain controversial for a number of reasons, including the fact that the population of patients treated was diverse and may have had pre-existing tumors or previous radiation and chemotherapy.

\section{GROWTH HORMONE AND AGING}

Greater availability of hGH has opened up new areas of research into the possibility of using it to slow or reverse the aging process. As people age, the function of the organ system deteriorates and the composition of the body begins to change. Lean body tissues such as muscles gradually are replaced by fat, and skin and bones become thinner and less pliable. Interestingly, these unwanted changes in body composition may correlate with the decreased levels of growth hormone that are produced by the body as one ages. A logical argument can be made that replacing the declining growth hormone levels with injections of growth hormone may slow or prevent these age-related changes. ${ }^{1,3}$

Several medical trials have been undertaken to test this idea. In 1990, Rudman et al. evaluated healthy men between the ages of 61 and 81 who received growth hormone injections for up to one year. ${ }^{1}$ The men showed a number of positive changes including an increase in their muscle mass, a decrease in body fat, and thickening of their skin. While the occurrence of side effects was minimal, the increase in blood sugar and blood pressure in some subjects could be cause for concern since persons of this age already are more susceptible to diabetes and high blood pressure. Unfortunately, another study looking at the effects of growth hormone in older women was not as promising. No improvement in the overall composition of their bodies was seen, and the ill effects of the treatment were such that only four out of 19 subjects finished the study.18,21 Ill effects included carpal tunnel syndrome and joint pain. However, the dose given these subjects was higher than that used in previous studies and might account for the ill effects.

Currently, the National Institutes of Health are funding several large-scale clinical trials looking at the effects of growth hormone in older adults, and the pharmaceutical industry is funding similar studies. However, at this point the value of using growth hormone in normal elderly persons is inconclusive at best. A recent editorial in the New England Journal of Medicine by Mary Vance, M.D., voiced the opinion that "because there are so many unanswered questions about the use of growth hormone in the elderly and in adults with growth hormone deficiency, its general use now and in the immediate future is not warranted and that scientific and financial resources would be better used in evaluating the effectiveness of hGH in patients with severe catabolic illness." 22 Dr. Vance also pointed out that the cost of one year's growth hormone therapy (according to the Rudman protocol) for an average adult would be $\$ 13,800$ (at 1990 costs) and that the long-term ill effects of this therapy are not yet known.

\section{GROWTH HORMONE ABUSES}

Although there is little medical and scientific evidence that growth hormone is some sort of 'fountain of youth,' a number of longevity 'spas' or 'clinics' outside of the U.S. are including growth hormone injections as part of youth-restoring regimens. On returning home, patients continue to be supplied with regular doses of growth hormone, often at a cost of $\$ 2,000$ to $\$ 4,000$ for a three-month supply. In addition to poor regulation of prescription drugs in many countries, U.S. citizens are able to take advantage of an FDA regulation that allows private citizens to import small quantities of unapproved medicines for personal use.

There also is growing concern that growth hormone may be abused by the sports and athletic communities. Some young athletes driven by the desire to win increasingly are turning to drugs such as anabolic steroids to enhance strength and performance. Growth hormone has body-building actions like steroids, but since it remains in the body for a shorter period of time, it is harder to detect. In addition, tests to detect growth hormone are not used as routinely by athletic commissions as those that detect steroids. There also seems to be a perception among athletes that growth hormone has fewer side effects than the anabolic steroids. A study to gauge how widespread the use of growth hormone is among young athletes in the Midwest found that $31 \%$ of high school students surveyed said they knew someone who was taking growth hormone for body-building purposes. ${ }^{23}$ Five percent of male athletes questioned said that they currently were using growth hormone. However, these numbers should be viewed with caution since pure hGH is expensive and difficult to obtain in this country. It is likely that a fair percentage of those who believe they are injecting growth hormone actually may be taking steroids, a diluted growth hormone mixture, or 
some completely unknown substance. This particularly is true if individuals get their product through illegal means or unregulated foreign sources.

Innate to the use of growth hormone for athletic enhancement or age reversal is the idea that if some growth hormone is good, more must be better. The belief that taking higher doses or more frequent injections of growth hormone can speed up or enhance its supposed beneficial effects can be a risky one. By increasing the amount of growth hormone taken, one may significantly increase the chance of serious side effects. While it may be some years before it is possible to accurately assess the dangers of growth hormone abuse, one need only consider the condition of acromegaly, where levels of growth hormone are elevated for many years, to see the detrimental effects on the body of prolonged excess growth hormone. Serious abnormalities of the heart, skeletal system, and nervous system are seen in these patients along with an increase in heart disease and tumors. Also, such abnormalities may be observed over time in persons who are misusing or abusing growth hormone.

As with many drugs, there is always a potential for misuse or abuse with growth hormone. However, the supply and distribution of human growth hormone is closely regulated by the U.S. pharmaceutical industry and it is available only through prescription in this country. Of course, it is possible for people to gain access to hGH in other countries where it is not regulated so closely, and this remains a concern.

\section{ECONOMIC ISSUES OF GROWTH HORMONE THERAPY}

In 1985 fewer than 4,000 individuals were receiving pituitary-derived growth hormone for treatment of growth hormone deficiency and Turner's syndrome. ${ }^{7,19}$ The limited usage was due in large part to the limited availability of the product. Today, the advent of recombinant human growth hormone has enabled the number of patients on hGH therapy to increase nearly tenfold. Last year in the U.S. alone, expenditures for growth hormone therapy approached $\$ 300$ million. ${ }^{7.19}$ With a health care system that progressively is being dominated by managed care organizations, the therapeutic uses of growth hormone are subject to renewed scrutiny. While most physicians and managed care providers recognize the necessity of hGH therapy in cases of clearly defined growth hormone deficiency or Turner's syndrome, its use to treat short stature remains controversial and is at the center of debate between physicians and health care organizations. From an economic standpoint, it may be argued that a yearly expenditure of up to $\$ 30,000$ or more to increase the final height of an essentially normal child is unwarranted, especially when data on the ability of hGH to increase that child's final height is still inconclusive. In addition, since broader clinical testing of hGH in elderly populations has become a reality in recent years, health care organizations soon may face the added dilemma of whether or not hGH is a justifiable option for preserving vigor and slowing the ravages of time in an aging population. Juxtaposed with the economic considerations are the ethical concerns regarding the potential risk of side effects from long-term growth therapy as well as the cost of treating these side effects if they arise.

\section{FUTURE OUTLOOK}

It is important not to lose sight of the valuable contributions growth hormone already has made and may continue to make to the overall well-being of many children and adults. Development of recombinant drugs such as hGH has been an important milestone in drug therapy, as they afford a safe, pure, and virtually unlimited supply of essential drugs. When used under the proper guidance of a physician, growth hormone has a minimum of side effects and is a valuable therapeutic agent in a number of disorders associated with poor growth. While some uses of growth hormone remain controversial, the full spectrum of future uses is only now being explored. In addition to its already-established use in children with poor growth, recent scientific research is raising the possibility that growth hormone may be an important drug in the battle against the wasting of body tissue that occurs when a person is bedridden with a prolonged illness or following trauma, surgery, severe burns, or incidence of AIDS infection. ${ }^{1,2,24-26}$ In addition, the ability of growth hormone to thicken bones may be an important finding for osteoporosis.

Clearly, hGH has tremendous possibilities-some that are known and others that are being explored. Managed care pharmacists should know whether or not hGH use is covered as part of the plan's pharmacy benefit. Some plans pay for this treatment while others don't. Additionally, it is important to know about prior authorization requirements regarding $\mathrm{hGH}$; such requirements are common to help avoid the types of abuse discussed in this article. Clinicians, both physicians and pharmacists, considering the use of this agent with their patients must carefully weigh the risks and benefits and make decisions on a case-by-case basis.
$\Delta \quad$ References
1. Rudman D, Feller AG, Hoskote S, et al. Effect of human growth hormone in men over 60. N Engl J Med 1990; 323: 1-6.
2. Wilson DM. Clinical actions of growth hormone. Endocrinol Met Clin North Am 1992; 519-37.
3. Walker C. Human growth hormone: the fountain of youth. Geriatrics 1990; 45: $18-19$
4. Casanueva FE. Physiology of growth hormone secretion and action
Endocrinol Met Clin North Am 1992; 21: 483-511.
5 . Raben MS. Clinical use of human growth hormone. N Engl J Med 1962; 266: $82-86$.
6. Kock TK, Berg BO, DeArmand SJ. Creutzfeldt-Jakob disease in a young adult with idiopathic hypopituitarism: possible relationship to administration of cadaveric human growth hormone. N Engl J Med 1985; 313: 731-33.
7. Neely KE, Rosenfeld RG. Use and abuse of human growth hormone. Ann Rev Med 1994; 45: 407-20
8. Bradley CA, Sodeman TM. Human growlh hormone: its use and abuse. 
Clin Lab Med 1990; 10: 471-74.

9. Underwood LE. Growth hormone therapy for short stature: yes or no. Hosp Pract 1992; 4: 192-98.

10. Albertsson-Wikland K. Growth hormone treatment in short childrenshort-term and long-term effects on growth. Acata Pediatr Scand 343: 77-84, 1988.

11. Wit JM, Fokker MH, deMuinck Keizer-Schrama MPE: Effects of two years of methionyl growth hormone therapy in two dose regimens in prepubertal children with short stature, subnormal rate, and normal growth hormone response to secretagogues. J Pediatr 1989; 115: 720-25. . i"

12. Hopewood N, Hintz RL, Gertner JM. Growth response of non-growth hormone-deficient children with marked short stature during three years of growth hormone therapy. J Pediatr 1993;123: 215-22.

13. Moran A, Brown DM, Doherty L, Ainslie M, Sane K, Saxena K, Sheridan $\mathrm{K}$, Spencer M, Sockalosky J, Ternand C. Diagnosis, monitoring and treatment of short stature in children: Twin cities community standards. Endocrinologist 5/4 1995: 272-77.

14. Siegel PK, Clopper R, Stabler B. Psychological impact of significantly short stature. Acta Paediatr Scand Suppl 1991; 377: 14-18.

15. Boultion TJ, Dunn SM, Quigley CA, Taylor JJ, Thompson L. Perceptions of self and short stature. Effects of two years of growth hormone treatment. Acta Paediatr Scand Suppl 1991; 377: 20-27.

16. Hopwood N, Herrtz RL, Gertner JM. Growth response of non-growth hormone-deficient children "with marked short stature to three years of growth hormone therapy. J Pediatr 1993; 123: 215-22

17. Rosenfeld RG, Frane J Attie KM. Six year results of a randomized prospective trial of human growth hormone and oxandrolone in Turner's syndrome. J Pediatr 1992; 121: 49-55.

18. Ho KKY, Hoffman DM. Aging and growth hormone. Horm Res 1993; 40: 80-86:

19. Watanabe S. Yamaguchi N. Tsuenmatsu Y, Komiyama A. Risk factors for leukemia among growth hormone users. Jpn J Cancer 1988; 80: 822-25.

20. Staahnke N, Zeisel HJ. Growth hormone therapy and leukemia: an update. Horm Res 1992; 38: 56-62.

21. Hintz Rl, Hoffman Al, Butterfield G, Marcus R. The effects and side effects of growth hormone treatment in adults - pros and cons. London, England; Freund, 1993.

22. Vance Ml. Growth hormone for the elderly. N Engl J Med 1990; 323: 52-55.

23. Ricker VL, Pawlak-Morello C, Sheppard V, Jay MS. Human growth hormone: a new substance of abuse among adolescents. Clin Ped 1992; 31: 723-26. 24. Fleming RY, Rutan RL, Jahor F. Effect of recombinant human growth hormone on catabolic hormones and free fatty acids following thermal injury. J of Trauma 1992; 36: 698-702.

25. Steele FR. Growth hormone and AIDS-related wasting. Nature Medicine 1996; 2 : 369-70.

26. Kupfer SR, Underwood LE, Bacter RC, Clemmons DR. Enhancement of the anabolic effects of growth hormone and insulin-like growth factor I by use of both agents simultaneously. J Clin Invest 1993; 91: 391-96. 